\title{
Management Model for Enhancing Effectiveness of Population and Health Programs: Case of Ismailia Governorate in Egypt
}

\author{
${ }^{1}$ Hoda Ibrahim Rizk, ${ }^{1}$ Madiha Said Abdel-Razik, ${ }^{2}$ Ahmed Samir Elsayad and ${ }^{1}$ Eman H. \\ El Habashi
}

${ }^{1}$ Public health and Community medicine, Faculty of medicine, Cairo University. ${ }^{2}$ Management and Marketing, formerly Faculty of Economics and Management, Sixth of October University.

Submitted:07-06-2020 Revised:28-07-2020 Accepted:29-07-2020

\begin{abstract}
Monitoring and Evaluation (M\&E) of Population and Health Programs (P\&HP) at district levels requires a holistic approach and tight collaboration between policy makers, implementing bodies and M\&E agencies. There is noted need for a management informational model that triggers areas where implementing agencies need to directly intervene, improving effectiveness of P\&HP. Objectives: To assess impact of communicating Districts' key performance indicators (KPIs) of P\&HP in an innovative management infograph model to decision and policy making Governorate Regional Population Council (GRPC). Method: An intervention Pre-test (2014) Post-test (2016) population-based study design was used. Study was conducted in Ismailia Governorate (IG) and National Population Council Head Quarter (NPC-HQ). The study was component of UN Population Fund project activities in NPC. Data was managed to have 26 indicators for eight categories. Deviation Scores (DS) from governorate level were estimated for seven IG districts and composite indices (CI) were presented in one info-graph to GRPC in 2015 to take actions and in 2017 to investigate impact of the actions taken. Results: Crude Birth Rate (CBR) decreased from $34 / 1000$ in 2014, to 31/1000 in 2016. Infant Mortality Rate (IMR) decreased from 11/1000 live births in 2014, to 7/1000 in 2016. Members of GRPC noted that during the period 20152016, extensive family planning campaigns through mobile clinics were particularly well distributed and placed, and particularly helped in increasing Contraceptive Coverage Rate (CCR) from $33 \%$ to $64 \%$. Conclusion: Communicating the info-graph management model of Districts' P\&HP KPIs to GRPC has resulted in more accurate interventions and improved effectiveness of programs.
\end{abstract}

Key Words: Egypt; CBR; IMR; CCR; Info-Graph Model; KPIs.

Corresponding Author:_Eman Moawad Elhabashi E-mail: address: Iman.Al-Habashi@kasralainy.edu.eg; Eman_Moawad@hotmail.com

\section{Introduction}

For the first time, according to the Egypt Constitution (2013), clause No. 41 emphasized guarantee of the country to implement population programs within the framework of sustainable development. ${ }^{1}$ Consequently, National Strategy for Population and Development 2015-2030 was issued in the year 2015 to support population programs through a multisectorial approach. ${ }^{2}$ Population strategy focuses on four themes; reducing population growth rate, Improving population characteristics, Geographic redistribution of the population, and 
closure of socioeconomic gaps between different segments of the population. ${ }^{2}$

Despite of having extensive MISs in different sectors all over Egypt, and the outcomes of quality research that gives out large amounts of processed data both supporting decision making with evidencebased updated information, there is limited usefulness for policy makers. Several studies focused on support to decision making by analyzing multi-sectorial data and developing a special model at the organization level to help in supporting the organizational capabilities and providing practical awareness to management. ${ }^{3}$ In Egypt, for an example, an ecological correlation study was done with the aim of setting alternative strategies for decision makers to follow, to be able to reduce children mortality rates. ${ }^{4}$ Development of composite indices (CI) are usually done to simplify huge data. Usually, CI are used in ranking at the level of countries, governorates and districts. ${ }^{5-6}$ For an example, using $\mathrm{CI}$ for calculating the incidence of communicable diseases (CD) across 27 governorates for seven consecutive years resulted in identification of the governorates with highest incidence for fifteen of the communicable diseases in Egypt. ${ }^{7}$ Deviation scores (DS) were used for the purpose of ranking and as tools to predict the potential for improving child health care programs' performance. ${ }^{8}$

Egypt National Population Council (NPC) is concerned with the mission of setting population policies, strategies and monitoring and evaluation of population programs. However, before 2014, there was no well-designed M\&E system for providing information to support decision making at the national, governorate and district levels.

The objective of this study is to assess impact of communicating Districts' key performance indicators (KPIs) of P\&HP in an innovative info-graph model to decision and policy making Governorate Regional Population Council (GRPC).

\section{Methods}

Study hypothesis: A KPI driven management info-graph guides policy makers to administrative location and functional categories for intervention (education, health resources, family planning etc.). This model prioritizes interventions by location and functional areas. The model is a tool for monitoring and evaluation for any population and health program that measures impact of interventions. It also allows identification of most effective interventions that enhance health of the population. The model delineates reasons of change in health status of different groups of population, and can be adopted by any country, governorate and organization, at national or international levels.

Independent variable: Preparation and communicating colored matrix that include key performance indicators (KPI) and indices by implementation sectors and districts, with Members of the Governorate Regional Population Council (GRPC), Dependent Variable: Improvement of population and health programs indicators, Intermediate variables: Informed members of GRPC, will take actions guided by priority sectors (education, health.) and priority at -risk districts.

Control factors included spectrum of authority and autonomy at governorate level to make changes at districts' level. Ministries as a central management level could have this authority.

The interventions to respond to recommendations derived from the discussed colored matrix for districts and sectors performance, could need more resources to achieve changes. 
The time elapsed between discussing the situation analysis matrix for year 2014 and assessment of performance for year 2016, allow for assessment of short-term strategies to make changes.

Demographic changes at national and governorate level and district level, could influence the measured indicators in the post test. Internal migration, redefining boundaries of districts could influence indicators at district level.

Study setting: The study was conducted in Ismailia Governorate (IG) and head quarter of National Population Council (NPC). IG is one of Lower Egypt Governorates, with total of 1303993 population according to 2017 census. ${ }^{9}$ IG is composed of seven districts. Governmental Health services are provided through 68 Primary health care facilities, five health offices and seven hospitals. ${ }^{10} \mathrm{IG}$ is one of the six priority governorates that included in NPC/M\&E and research program for improving $\mathrm{P} \& \mathrm{HP}$ indicators. $^{11}$

Sources of data: Governorate's MISs providing secondary data related to all the ministries involved in reporting data to NPC at governorate level then NPC at central level.

Study design: Pretest-posttest intervention study, population and institutional -based study

The pre-test: Situation analysis was described as info-graph/matrix for P\&HP KPIs at district level for year 2014 (explained in the model)

Intervention: Participation of one of the researchers in the three-monthly meeting of GRPC in IG March 2015. Communication of information illustrated in the info-graph for P\&HP KPIs 2014, and setting guidelines for improvement at different sectors were discussed and documented for follow up every three months during GRPC meetings.
The Posttest: An info-graph for P\&HP KPIs 2016, was communicated with GRPC members in June 2017 to explain the causes of changes between 2014 and 2016. Steps of the Practical Model for Improving Effectiveness of Population \&Health Programs (PMIEP\&HP):

Data are collected by NPC-Governorate offices and processed to develop 26 indicators at district and governorate levels.

The value of each of the twenty-six indicators at governorate level was considered as the acceptable standard to be compared to.

The 26 indicators were organized in computer excel sheets, then divided into eight categories, as follows.

Population Characteristics Index (8 indicators): Percent of District's population size to total governorate population, Percent of females to total population at district level, Female to Male ratio at birth, Percent of married females at childbearing period (MFCBP) at district level to total MFCBP at governorate level, Percent of rural population, Total age dependency ratio, Young age (less than 15 years) dependency ratio and Old age (65 and more) dependency ratio.

Education Services Resources Index (6 indicators): Average number of students per class and average number of students per Teacher in each stage of the education in primary, Preparatory, and secondary schools

Health Services Resources Index: (5 indicators): Nurses to Physicians ratio, MOHP Health Units per 100,000 population, Physicians per 10,000 population, Nurses per 10,000 population, and Governmental hospital beds per 10,000 population

Non-Governmental Organizations (NGO) availability: (one indicator): Average number of population served by one NGO 
Family Planning outcome: (one indicator): Contraceptive Coverage Rate (CCR)

Impact indicators for Child Health (3 indicators): Neonatal mortality rate, Infant Mortality rate, Under-five mortality per 1000 Under-five children.

Impact indicator for Population Change: (one indicator): Rate of Natural Increase (RNI).

Impact indicator for Family Planning Program: (one indicator): Crude Birth Rate (CBR).

Development of deviation score for each indicator at district level: Calculation of the 26 deviation scores for each district with the following equation: (Value of the indicator at district level - Value of same indicator at governorate level) $* 100$ divided by the value of same indicator at governorate level.

Interpretation of the deviation score for each indicator: For population characteristics' eight indicators, Education services resources' six Indicators, NGOs availability indicator, child's health three impact indicators, CBR indicator and RNI indicator: if the DSs have negative sign (-) this indicates favorable situation and if the DSs have positive sign (+)this indicates unfavorable situation. While for Health services resources' five indicators and CCR indicator: if the DSs have positive sign (+) this indicates favorable situation and if the DSs have negative sign (-) this indicates unfavorable situation.

Development of composite indices: The index is calculated as the sum of DSstaking positive and negative signs into consideration- for each group of indicators assigned to special category.

Design a matrix/info-graph to illustrate P\&HP KPIs for each of the governorate's District: The matrix is composed of all the indicators and their calculated DSs and the total score for each district (estimated by simple ranking). The districts are ranked vertically according to each category of the index: population characteristics' index, Education services resources' index, NGOs availability indicator, child's health impact indicators, CBR indicator and RNI indicator: from lowest to highest while for Health services resources' index and CCR indicator: from highest to lowest. Colored one sheet Infograph was presented into a power point presentation to policy makers.

The colored sheet (green zones $=$ favorable situation and red zone $=$ unfavorable situation) is self-explanatory. Open discussions with policy making presenters from many different sectors were held to describe challenges facing each district regarding its situation related to the 26 indicators. In Egypt, the Governorate Regional Population Council (GRPC) has regular meetings every three months. The director of NPC-governorate office presented the info-graph in each meeting and reported decisions and interventions to central level of M\&E - NPC.

Assessment of impact of communicating the PMIEP\&HP with policy makers, after two years of interventions using the same KPIs for the P\&HP.

The previous seven steps were repeated again in 2016 to develop a new infograph. The new info graph was used to guide discussions for changes in policies and strategies and learned lessons. The cycle has to be repeated every two years to build on strengths and opportunities, and to overcome weaknesses and challenges for supporting P\&HP.

Another dimension for the relation between KPIs and impact indicators was considered as Independent Dynamics Index (IDI) included population characteristics, education services resources, health services resources and NGOs resources, and Family PlanningCCR indices and Dependent Dynamics 
Index (DDI) composed of children mortality index, CBR, and RNI.

Notably, the model intentionally depended on using readily available and common programs for data analysis (Excel program) not on proprietary statistical packages, facilitating the model's real use by decision makers and individuals with different backgrounds and skills.

Accordingly, the current study has provided an easy and accessible management model for improving effectiveness of Population \& Health Programs that depends on available MIS annual data and encourages active actions taking by districts and organizations decision makers according to information derived from the info-graph model. The info-graphs have to be discussed with Governorate Regional Population Council (GRPC) to develop information-based decisions to improve population development programs in priority districts and priority development sector (e.g. health, education etc.,). Three- monthly meetings of NPC-M\&E department members with GRPC members allow for discussing changes over time in KPIs for Population Programs.

\section{Ethical Standard}

All procedures performed involving human participants were in accordance with the ethical standards of the institutional and/or national research committee and with the 1964 Helsinki declaration and its later amendments or comparable ethical standards [36]. Informed consent was obtained from all individual participants included in the study.

\section{Results}

Info-graph (1) illustrates a portrait for IG districts' regarding P\&HP indices (4 indicators and 4 indices) and ranking of each district's KPIs from the best/favorable situation (number 1) to critical/unfavorable situation (number 7). The info-graph showed also DSs or KPIs for IG districts from their governorate level (2014). The total KPIs' score for the seven districts indicated that "Tal-Kaber" district ranked the best (63\%) among all seven districts. The positive potentials for "TalKaber" district were mainly attributed to high DS for education services resources, health services resources, family planning (FP) services and children mortality index. However, the same district reported moderate DS for CBR and RNI.

"West Quantara" District ranked the seventh district regarding total KPI score $(30 \%)$. This critical position was attributed to shortage in education services resources with $\mathrm{DS}=-12 \%$, health services resources with $\mathrm{DS}=-12 \%$ and family planning services with $\mathrm{DS}=-43 \%$. The high DS for RNI (44\%) and CBR (29\%) indicated high rate of population increase.

Table (1) demonstrated percent distribution of population all over the seven districts, vital statistics such as; CBR, Crude Death Rate, RNI and children mortality index and CCR across IG districts for year 2014 versus 2016. It is obvious that IG was exposed to population dynamics that resulted in re-demarcation of borders across districts between 2014 and 2016. It is clear that CCR showed marked increase by $31 \%$ (from $33 \%$ in 2014 to $64 \%$ in 2016). However, such changes in CCR showed variations across IG districts with obvious increase in districts identified as critical districts in 2014 i.e. "West Quantara" (83\%), and "Kasasen" (45\%). The CBR showed decrease from 34 (2014) to 31 births / 1000 populations in 2016. The decrease in CBR was obvious in "West Quantara" from 44 to 36 births /1000 population. 
Info-graph (2) showed situation in all seven IG Districts in 2016 concerning districts' distribution according to P\&HP KPIs, and DSs. "Tal-Kaber" kept its first position. Yet, other districts showed marked changes across most of the infograph. "West Quantara" district which ranked no 7 in 2014 (total score was 34\%), showed improvement to be in the fifth position with total score of $50 \%$.

As represented from table (2) in 2014, the net increase in IDI /resources above IG level was 32 percent points. DDI /impact on the community showed high level 25 percent point. The net shortfall in capitalizing on resources across districts equal -56 percent. The gap between IDI and DDI at district level ranged between ($131 \%)$ in Ismailia District and $(+56 \%)$ in "Abo Sewer" District. In 2016 the total IDI was $-32 \%$. DDI presented as total DS scores was $44 \%$ higher satisfactory level than the average for governorate. Consequently, the net achievements in total KPIs for H\&PP was $76 \%$. The net achievement score in "Faied" district was $60 \%$. The IDI index was less than the average by $30 \%$ and the DDI was more than average by $30 \%$.

Communication of findings with GRPC members in 2017 delineated that, throughout the period 2014 - 2016 there was re-demarcation of borders between districts and extensive campaigns through mobile clinics were well distributed providing fee-free FP and Reproductive Health $(\mathrm{RH})$ services.

\section{Discussion}

The study deliberated a unique model that embraces several issues in public health programs, applied research, and decision making through: Holistic/multi-sectorial approach, Decentralization, Information system, Governance and Equity. Multisectorial approach included demographic profile, education services resources, health services resources, NGOs availability, FP, children mortality index, CBR and RNI. The approach of linking socio-demographic indicators with health system was considered as a difficult issue. ${ }^{12}$ Other studies emphasized relations between socioeconomic standard and health problems at the community level. ${ }^{13-}$ 14 Despite recent approaches focuses on prediction of population medical indices through using social media ${ }^{15-16}$, its generalization across countries had limitations, because they were individually oriented. Decentralization was demonstrated in the practical model through working at district levels. Decentralization is crucial in planning, implementation and monitoring and evaluation. ${ }^{17}$ Findings give emphasis to the need for decentralization, for example; in 2014, health services resources index showed DS at $43 \%$ for "Tal-Kaber" District, and shortage in resources by $32 \%$ DS in "Abo-Sware" District. In 2016, the DS for the same index was $68 \%$ for "Tal-Kaber" and $-8 \%$ for "AboSware". Such findings could not be related to redistribution of resources, it is assumed to be due to increase in population size, migration and demarcation of borders of districts. This assumption can be supported by population dynamics which took place in IG 2015-2018. According to census 2006 and $2017^{9}$, the total Egyptian population showed increase by $30.6 \%$, yet in IG, the population increase was $38.3 \%$. IG received migrants from Saini during the period 2015-2018. There was decrease in South Saini population between the two census years - 32\%. Additionally, administrative re-demarcation of districts' boundaries took place i.e. part of geographic region with its resources had been affiliated from one district to another 
(table 1). The governmental health units (HU) did not show increase in IG. In 2014 there were $9.4 \mathrm{HU} / 100000$ population, 7.7 in 2016 and 5.2 in 2018 according to MOHP statistics 2018. ${ }^{10}$ In Egypt, the total number of physicians in the current workforce in the governmental sector is 188535 physicians with 1.88 physicians per 1000 population [Egyptian Medical Syndicate, 2019: Unpublished Information Center registries]. In the current study, physicians per 10000 population in IG was 7.1 and 7.3 in 2014 and 2016 respectively. However, decentralization initiatives after intervention showed, redistribution of physicians in Ismailia District with decrease from 39 to nine/10000 population [Population Information Center; National Population Council, Egypt: 2014 - 2016: Unpublished report].

Decentralization is evidenced to be effective approach to increase efficiency and outcome of the health system. ${ }^{18-19-20}$ The changes in districts' geographical boundaries and keeping their names, made comparison before and after intervention to be accepted, because of using methodology of DS for years 2014 and 2016.

The dynamics of knowledge production in context of program implementation and follow-up lead to defining strategies for improved management. ${ }^{21}$ The model used MISs subordinated to different ministries to build up a matrix with articulation of socioeconomic indices and health outcome. Using aggregated indicators for different organizations facilitates access towards promotion of health and social development. ${ }^{5-7-8,22}$ The contextual framework of using Composite Indices (CI) is based on mathematical aggregation of a set of sub-indicators for measuring multi-dimension concepts that cannot be captured by a single indicator. ${ }^{23}$ The study model is based on categorizing indicators to be communicated with policy makers in each sector to improve situation in specific district defined as critical vis-à-vis resources and outcome as supported by other studies in Indonesia. ${ }^{24}$

Aggregation of indicators allowed for working on two major groups of $\mathrm{CI}$ : Independent Dynamic Indices (IDI) as demographic characteristics and resources and Dependent Dynamic Indices (DDI) children mortality index and CBR. The relation between those two indices were studied to represent actual or potential needs for reducing health problems. ${ }^{12,25-28}$ Therefore, both IDI and DDI have to improve the situation in specific district defined as critical vis-à-vis resources and outcomes to be considered during evaluating policy initiatives such as the Millennium Development Goals and Sustainable Development Goals and set more accurate, country-specific development targets. $^{29}$ Equity across districts/communities has been always one of World Health Organization main objectives. $^{30}$ Equity in access to health services $^{31}$ and education services ${ }^{32}$ were emphasized through multi-sectorial approaches. Additionally, governance was introduced to the study through directing decision making through presenting their performance across different sectors and districts. There are evidence that good governance will ultimately lead to better health outcomes. ${ }^{33-34}$ One of the key findings for policy maker's response was a short-term strategy through using mobile clinics to overcome shortage in family planning services and increase in CCR and reduce CBR (Table 1). Despite mobile clinics are not efficient in terms of high cost per client compared to fixed clinics in rural areas, they provide appropriateness for policy makers to increase CCR due to high acceptability for women who get feefree FP/RH and FP methods [According to 
El-Zanaty and Associates in 2001. Sustainability of Mobile Clinics in reproductive Health and Family Planning Service Delivery. National Population Council, USAID: Unpublished project.]. Similar study was conducted in Giza Egypt governorate and the used infograph in the current study was termed District Enactment Matrix and included 19 districts. The posttest findings showed that all districts in the red zone and two districts in the yellow zone had demonstrated positive changes in 28 KPIs. In the present study, the same intervention resulted in improvement in KPI in population programs. The CCR showed increase from $38 \%$ in 2014 to be $49 \%$ in 2016. The crude birth rate showed decrease from 31 births/1000 population in 2014 to be 28.8 births/ 1000 in $2016 .{ }^{35}$

Strengths of the study are related to using information system, and participatory nature between researchers, implementing agencies, and NPC monitoring and evaluation staff and policy makers. Expanding such type of studies across Egypt governorates will come into different determinants, as experienced from each governorate that could contribute in improving population and health programs. The study is one of the ecological studies that is concerned with population data rather than individual data. The limitations are related to study design which are related to ecological correlation studies with inability to link exposure to outcome, due to many confounders. ${ }^{13}$ However, the methodology of the study and the tested model could be generalized at national and international levels and across different health and development sectors. The applicability of the model is evidenced by NPC/M\&E data and its testing by research studies for two governorates i.e. Giza ${ }^{35}$ and Ismailia.
The Implication of the present study on improving effectiveness of population programs is for improving effectiveness of population programs guided by key performance indicators, it is crucial to develop a package of strategies and interventions to be adopted by policy and decision makers. The process of development of short and long-term strategies needs working through management cycle that link between information system, communication for informing policy and action takers, implementation of remedial intervention, and assessment of post intervention changes. Using data derived from different governmental sectors with subsequent manipulation to develop colored infograph is essential to facilitate identification of at-risk districts regarding population and health status. The model allowed communication with policy makers with different backgrounds by using traffic signs to highlight areas that need intervention. The model depended on using simple available program for data analysis (Excel program) facilitating its use by decision makers and individuals with different backgrounds and skills.

\section{Conclusion}

The practical model of communicating multi-sectorial-population and Health KPIs with policy makers, sets roadmap for implementing agencies to adopt strategies that increase effectiveness of population and health programs.

\section{References:}

1. Arab Republic of Egypt Constitution; 2013. Available from: http:// www.youth.gov.eg [accessed 20 December 2018].

2. Egypt Ministry of Population; 2015. National Strategy for Population and Development; 2015 - 2030. Available from: https://egypt.unfpa.org/en/node/ 22541 [accessed 10 December 2018]. 
3. Wang, Y., Kung, L. A., Wang, W. Y. C., and Cegielski, C. G. An integrated big data analytics-enabled transformation model: Application to health care. Information and Management. 2018; 55(1), 64-79. https://doi.org/10.1016/j.im.2017.04.001

4. Abdel-Razik M.S.M., El-Rabbat M, Kamal Elden NM and Ali HZY. Ecological Study to Set Alternative Strategies for Reducing Child Mortality. Epidemiology Biostatistics and Public Health. 2015; 12(3).

5. Institute of National Planning (INP). Human Development Report. Egypt: United Nations Development Programs; 2011. Available from: http://hdr.undp.org.

6. El-Gohary R O, Abdel-Ghany M A and ElAbasy a M. Determinants of Human Development in Egypt (Analytical study from World Bank 1990 -2013) Arab Family Health and Population- League of Arab States. 2016; 9 (21).

7. Abdel-Razik M.S.M., Rizk HII and Hassan MHM. Surveillance of communicable diseases for decision making in Egypt 2006-2013. Eastern Mediterranean Health Journal.2017; 23(6).

8. Abdel-Razik M.S.M. and Abou Zeina H.A. Compound Deviation Indices: Tools to predict potential for improving child health care programs' performance. The Medical Journal of Cairo University. 2005; 73(3).

9. Central Agency for Public Mobilization and Statistics (CAPMAS): Egypt Census Report; 2006-2017.

10. Health Information System: Egypt Ministry of Health and Population report 2018. 11. Anwer W. Demographic and Health Indicators for selected Governorates in Egypt: Sharkia, Behera, Ismailia, Mynia, Asuit, and Souhag. Faculty of Medicine, Community Medicine Department and National Population Council, 2017.

12. Joseph A E and Hollett RG. The use of socio-demographic indicators in local health planning: A Canadian non- metropolitan perspective. Sot. Sri. Med.1993; 37(6): 813822.

13. Mulligan J, Appleby J. and Harrison A. Measuring the performance of the health systems: Indicators still fail to take socioeconomic factors into account. BMJ.
2000; 321:191. doi: https://doi.org/10.1136/bmj.321.7255.191

14. Myint PK, Luben RN, Surtees PG, Wainwright NW, Bingham SA, Wareham $\mathrm{NJ}$ and Khaw KT. Effect of age and sex on the relationship between different socioeconomic indices and self-reported functional health in the EPIC-Norfolk population-based study. Ann Epidemiol. 2009; 19(5):289-97. Doi: 10.1016/j.annepidem.2009.02.003.

15. Thin N; Duc Thanh N; MarkE L; Bridianne O; John Y; Dinh P, Svetha V and Helen C. Prediction of population health indices from social media using kernel-based textual and temporal features: 26th International World Wide Web Conference 2017, WWW 2017 Companion, p 99-107. https://dl.acm.org/citation.cfm?id=3054136

16. Colom M, Austad K, Sacuj N, Larson $\mathrm{K}$ and Rohloff $\mathrm{P}$. Expanding access to primary healthcare for women through a microfinance institution: A case study from rural Guatemala. HEALTHCARE-THE JOURNAL OF DELIVERY SCIENCE AND INNOVATION. 2018; 6(4): 223-230.

17. MOHP. District Provider Organization Guidelines-Summary and Outlines - Sector of Technical Support and Projects - HSRP (2004). www.hsrp.gov.eg [accessed 20.10.2018].

18. Hurley J., Birch S. \& Eyles J. Geographically decentralized planning and management in health care: some informational issues and their implications for efficiency. Soc Sci Med. 1995; 41 (1):3-11.

19. Kaarakainen M; Rissanen S and Kinnunen J. Long Waves of Decentralization in Public Management: A Case Study of Finnish Public Health Care. World Future Review. 2010; 2(2):29-40 https://journals.sagepub.com/doi/ $\underline{10.1177 / 194675671000200206}$

20. Panda B, Thakur HP. Decentralization and health system performance - a focused review of dimensions, difficulties, and derivatives in India. BMC Health Serv Res. 2016; 16 (Suppl 6): 561. doi: 10.1186/s12913-016-1784-9.

21. Feltrin RB, Guilam MCR, Cristina M, Barral-netto M , Lima NT. and Moraes MO. For socially engaged science: The dynamics of knowledge production in the Fiocruz graduate program in the framework of 
the "Brazil without Extreme Poverty Plan. PLoS One. 2018; 13(10): e0204232 doi: 10.1371/journal.pone.0204232

https://www.ncbi.nlm.nih.gov/pmc/articles/PM C6195260/

22. Battakova ZE, Slazhneva TI, Darisheva MA, Kudasheva TV and Darisheva DA. Evaluation of human capital using the life quality and population health indices in Kazakhstan. : International Scientific Forum of the 6th Ryskulov's Readings - Socio-Economic Modernization of Kazakhstan Under Conditions of Global Financial Instability Proceedings Paper SOCIO-ECONOMIC MODERNIZATION OF KAZAKHSTAN UNDER CONDITIONS OF GLOBAL FINANCIAL INSTABILITY Book Group Author(s): Ryskulov T, Kazakh Economic University. 2012; 1601-162.

23. Bernini C., Guizzardi A. and Angelini G. Developing a Composite Indicator of Residents' Well-Being: The Case of the Romagna Area. In: Crescenzi F., Mignani S. (eds) Statistical Methods and Applications from a Historical Perspective. Studies in Theoretical and Applied Statistics. Springer, Cham. 2014; DOI: https://doi.org/10.1007/978-3-319-05552-7_29 24. Surjadi E, Aryastami K and Kosen S. The integrated health services information system to support the sustainability of health care delivery system in Indonesia. 2000; 586-591 vol.2. 10.1109/ICMIT.2000.916758. DOI: 10.1109/ICMIT.2000.916758

25. Abdel-Razik M.S.A, Abdel-Hai R and Ibrahim H. Reasons of reduction in contraceptive coverage rate in Egypt 20022007, the National Population Council Research Project, 2008. https://egypt.unfpa.org /sites/default/files/pub-pdf/d1fc9824-8573422a-a8b1-1724171a75cc.pdf

26. El-Zanaty and Associates. Reproductive health impact of family health model pilots in Egypt. MOHP and UNFPA and El-Zanaty \&Associates. January 2011 https://egypt.unfpa.org/en/publications/studyreproductive-health-impact-family-healthmodel-pilots-egypt

27. El-Zanaty and Associates, Ministry of Health and Population\& ICF International, 2015. Egypt Demographic and Health Survey
2014. Cairo, Egypt and Rockville, Maryland, USA: Ministry of Health and Population and ICF International. https://dhsprogram.com /pubs/pdf/FR302/FR302.pdf

28. Berlie AB and Alamerew YT. Determinants of Fertility Rate among Reproductive Age Women (15-49) in GonjiKollela District of the Amhara National Regional State, Ethiopia. Ethiopian Journal of Health Development. 2018; 32(3): 144-155

29. Ranganathan S, Swain RB and Sumpter DJ. The demographic transition and economic growth: implications for development policy. Palgrave Communications. 2015; 1(15033). https://www.nature.com/articles/palcomms 201533

30. World Development Report, 2006. Overview [pdf 203kb], Independent Inquiry into Inequalities in Health Report https://www.who.int/healthsystems/topics/equi ty/en/ [accessed 1 October 2018].

31. Chedid RA and Phillips KP. Best Practices for the Design, Implementation and Evaluation of Prenatal Health Programs. MATERNAL AND CHILD HEALTH JOURNAL. 2019; 23(1): 109-119

32. Mann B. and Baker DP. Cyber Charter Schools and Growing Resource Inequality among Public Districts: Geospatial Patterns and Consequences of a Statewide Choice Policy in Pennsylvania, 2002-2014. American Journal of Education. 2019; 125 (2):147-171. 33. Barbazza E. and Tello JE. A review of health governance: Definitions, dimensions and tools to govern Health Policy. Epub. 2014; 116(1):1-11. Doi: 10.1016/j.healthpol. 2014.01.007.

34. WHO | Governance - World Health Organization https://www.who.int/ healthsystems/topics/stewardship/en/ [accessed 11 December 2018].

35. Abdel-Razik M.S.A and Salem MR. From public health and demographic research to decision making: An intervention study in Giza Governorate-Egypt. Evaluation and program planning. 2019; 77:101704. DOI: 10.1016/j.evalprogplan.2019.101704

36. DECLARATION OF HELSINKI, 1964. Recommendations guiding doctors in clinical 
research, World Medical Assembly, Helsinki, Finland.

Table legend:

Info-graph (1): Ismailia Districts according to Deviation Score for districts' population indicators from the governorate's indicators (2014)

Table (1): Contraceptive Coverage Rate (CCR), Mortality and Birth rate Statistics for year 2014 versus 2016, in 7 districts of Ismailia Governorate

Info-graph (2): Ismailia Districts according to Deviation Score for districts' population indicators from the governorate's indicators (2016)

Table (2): Ismailia Districts by deviation scores for Independent Dynamic Index (Population characteristics, education resources, Health services resources, NGOs* and CCR*) versus Dependent Dynamic index (neonatal, infant, U5 mortality, $\mathrm{CBR}^{*}, \mathrm{CDR}^{*}$ and $\left.\mathrm{RNI}^{*}\right)$ in 2014 versus 2016. 
Info-graph (1): Ismailia Districts according to Deviation Score for districts' population indicators from the governorate's indicators (2014)

\begin{tabular}{|c|c|c|c|c|c|c|c|c|c|c|c|c|c|c|c|c|c|c|}
\hline PC & $\mathrm{C}$ & ER & $\mathrm{C}$ & HR & $\mathrm{C}$ & NGOs & 1920 & FP-CCR & $33 \%$ & CM & $\mathrm{C}$ & RNI & 0.28 & CBR & 34.0 & Districts & Total & Do \\
\hline Districts & DS & Districts & DS & Districts & DS & Districts & $\%$ NGO & Districts & DS & Districts & DS & Districts & DS & Districts & DS & Total & Score & Kank \\
\hline EQ & $-15 \%$ & TK & $-9 \%$ & IS & $302 \%$ & IS & $-8 \%$ & IS & $60 \%$ & $\mathbf{F}$ & $-65 \%$ & AS & $-14 \%$ & AS & $-18 \%$ & TK & $63 \%$ & 1 \\
\hline $\mathbf{K}$ & $-5 \%$ & $\mathbf{F}$ & $-7 \%$ & TK & $43 \%$ & EQ & $4 \%$ & EQ & $51 \%$ & TK & $-62 \%$ & $\mathbf{F}$ & $-11 \%$ & $\mathbf{F}$ & $-15 \%$ & IS & $61 \%$ & 2 \\
\hline TK & $-2 \%$ & EQ & $-1 \%$ & EQ & $29 \%$ & WQ & $15 \%$ & $\mathbf{K}$ & $50 \%$ & AS & $-42 \%$ & IS & $1 \%$ & IS & $-6 \%$ & $\mathbf{F}$ & $59 \%$ & 3 \\
\hline $\mathbf{F}$ & $-1 \%$ & $\mathbf{K}$ & $2 \%$ & $\mathbf{K}$ & $17 \%$ & TK & $23 \%$ & TK & $36 \%$ & WQ & $-39 \%$ & TK & $11 \%$ & TK & $6 \%$ & EQ & $48 \%$ & 4 \\
\hline WQ & $1 \%$ & $\mathbf{A S}$ & $3 \%$ & $\mathbf{F}$ & $-9 \%$ & AS & $55 \%$ & $\mathbf{F}$ & $-16 \%$ & $\mathbf{K}$ & $-36 \%$ & $\mathbf{K}$ & $16 \%$ & $\mathbf{K}$ & $12 \%$ & AS & $48 \%$ & 5 \\
\hline AS & $15 \%$ & IS & $10 \%$ & WQ & $-12 \%$ & $\mathbf{F}$ & $92 \%$ & WQ & $-43 \%$ & EQ & $-6 \%$ & EQ & $41 \%$ & WQ & $29 \%$ & $\mathbf{K}$ & $41 \%$ & 6 \\
\hline IS & $24 \%$ & WQ & $12 \%$ & AS & $-32 \%$ & $\mathbf{K}$ & $100 \%$ & AS & $-54 \%$ & IS & $195 \%$ & WQ & $44 \%$ & EQ & $32 \%$ & WQ & $30 \%$ & 7 \\
\hline
\end{tabular}

PC=Population characteristics, C=Composite, ER=Education Resources, HR=Health Resources, NGOs=Non-Governmental Organization, FPCCR=Family PlanningContraception Coverage Rate, CM=Child Mortality, RNI=Rate of Natural Increase, CBR=Crude Birth Rate, DS=Deviation score, TK=Tal ElKebeer, Is=Ismailia, EQ=East Qantara, WQ=West Qantara, $A S=$ Abou Sweer, F=Fayed, K=Kassassin.

Table (1): Contraceptive Coverage Rate (CCR), Mortality and Birth rate Statistics for year 2014 versus 2016, in 7 districts of Ismailia Governorate

\begin{tabular}{|c|c|c|c|c|c|c|c|c|c|c|c|c|c|c|c|c|}
\hline \multirow[t]{2}{*}{ Districts } & \multicolumn{2}{|c|}{$\begin{array}{l}\text { Percent of } \\
\text { Pop to Govern }\end{array}$} & \multicolumn{2}{|c|}{ FP-CCR } & \multicolumn{2}{|c|}{$\begin{array}{l}\text { Neonatal } \\
\text { Mortality } \\
\text { Rate }\end{array}$} & \multicolumn{2}{|c|}{$\begin{array}{l}\text { Infant } \\
\text { Mortality } \\
\text { Rate }\end{array}$} & \multicolumn{2}{|c|}{$\begin{array}{l}\text { U5 Mortality } \\
\text { Rate }\end{array}$} & \multicolumn{2}{|c|}{$\begin{array}{l}\text { Crude Birth } \\
\text { Rate }\end{array}$} & \multicolumn{2}{|c|}{$\begin{array}{l}\text { Crude Death } \\
\text { Rate }\end{array}$} & \multicolumn{2}{|c|}{$\begin{array}{ll}\text { Rate of } \\
\text { Natural } \\
\text { Increase }\end{array}$} \\
\hline & 2014 & 2016 & 2014 & 2016 & 2014 & 2016 & 2014 & 2016 & 2014 & 2016 & 2014 & 2016 & 2014 & 2016 & 2014 & 2016 \\
\hline Tal Kabeir & $16 \%$ & $9 \%$ & $45 \%$ & $34 \%$ & $\mathbf{0}$ & 2 & 6 & 6 & 3 & 2 & 36 & 30 & 5 & 4 & 31.1 & 25.6 \\
\hline Ismailia & $41 \%$ & $41 \%$ & $53 \%$ & $61 \%$ & 10 & 15 & 18 & 9 & 26 & 24 & 32 & 31 & 4 & 9 & 28.2 & 21.8 \\
\hline Faied & $8 \%$ & $11 \%$ & $26 \%$ & $96 \%$ & 1 & 2 & 5 & 7 & 2 & 2 & 29 & 25 & 4 & 4 & 24.9 & 21.5 \\
\hline East Qantra & $11 \%$ & $4 \%$ & $50 \%$ & $63 \%$ & 3 & 2 & 9 & 8 & 7 & 5 & 45 & 42 & 5 & 4 & 39.6 & 37.2 \\
\hline Abo Swire & $12 \%$ & $16 \%$ & $15 \%$ & $55 \%$ & 2 & 1 & 8 & 6 & 3 & 2 & 28 & 25 & 3 & 3 & 24.2 & 21.3 \\
\hline Kasasin & $5 \%$ & $8 \%$ & $49 \%$ & $94 \%$ & 3 & 2 & 8 & 7 & 3 & 4 & 38 & 38 & 5 & 6 & 32.6 & 31.9 \\
\hline West Qantra & $9 \%$ & $11 \%$ & $19 \%$ & $102 \%$ & 2 & 2 & 7 & 5 & 4 & 3 & 44 & 36 & 4 & 4 & 40.2 & 32.2 \\
\hline Total & $100 \%$ & $100 \%$ & $33 \%$ & $64 \%$ & 5 & 7 & 11 & 7 & 5 & 6 & 34 & 31 & 6 & 6 & 28.0 & 24.6 \\
\hline
\end{tabular}


Info-graph (2): Ismailia Districts according to Deviation Score for districts' population indicators from the governorate's indicators (2016)

\begin{tabular}{|c|c|c|c|c|c|c|c|c|c|c|c|c|c|c|c|c|c|c|}
\hline PC & $\mathrm{C}$ & ER & $\mathrm{C}$ & HR & $\mathrm{C}$ & NGOs & 1906 & FP-CCR & $64 \%$ & $\mathbf{C M}$ & $\mathrm{C}$ & RNI & $25.0 \%$ & CBR & 30.76 & Districts & Total & Do \\
\hline Districts & DS & Districts & DS & Districts & DS & Districts & $\%$ NGO & Districts & DS & Districts & DS & Districts & DS & Districts & DS & Tot & Score & Капк \\
\hline EQ & $-8 \%$ & TK & $-9 \%$ & TK & $68 \%$ & IS & $-30 \%$ & TK & $60 \%$ & WQ & $-62 \%$ & AS & $-14 \%$ & AS & $20.1 \%$ & TK & $80 \%$ & 1 \\
\hline $\mathbf{K}$ & $2 \%$ & EQ & $-2 \%$ & IS & $7 \%$ & WQ & $18 \%$ & EQ & $46 \%$ & TK & $-62 \%$ & IS & $-11 \%$ & TK & $-3.9 \%$ & AS & $59 \%$ & 3 \\
\hline $\mathbf{F}$ & $2 \%$ & AS & $3 \%$ & $\mathbf{K}$ & $-6 \%$ & TK & $21 \%$ & WQ & $-2 \%$ & $\mathbf{F}$ & $-59 \%$ & TK & $4 \%$ & IS & $0.5 \%$ & IS & $57 \%$ & 4 \\
\hline WQ & $4 \%$ & WQ & $4 \%$ & AS & $-8 \%$ & AS & $57 \%$ & IS & $-4 \%$ & $\mathbf{K}$ & $-45 \%$ & $\mathbf{K}$ & $30 \%$ & WQ & $16.8 \%$ & WQ & $50 \%$ & 5 \\
\hline AS & $9 \%$ & $\mathbf{K}$ & $14 \%$ & $\mathbf{F}$ & $-9 \%$ & $\mathbf{F}$ & $88 \%$ & $\mathbf{F}$ & $-14 \%$ & EQ & $-41 \%$ & WQ & $31 \%$ & $\mathbf{K}$ & $22.9 \%$ & $\mathbf{F}$ & $48 \%$ & 6 \\
\hline IS & $18 \%$ & $\mathbf{F}$ & $38 \%$ & WQ & $-24 \%$ & $\mathbf{K}$ & $131 \%$ & AS & $-47 \%$ & IS & $87 \%$ & EQ & $51 \%$ & EQ & $35.0 \%$ & $\mathbf{K}$ & $46 \%$ & 7 \\
\hline
\end{tabular}

PC=Population characteristics, C=Composite, ER=Education Resources, HR=Health Resources, NGOs=Non-Governmental Organization, FPCCR=Family PlanningContraception Coverage Rate, CM=Child Mortality, RNI=Rate of Natural Increase, CBR=Crude Birth Rate, DS=Deviation score, TK=Tal ElKebeer, Is=Ismailia, EQ=East Qantara, WQ=West Qantara, $A S=$ Abou Sweer, $F=$ Fayed, K=Kassassin.

Table (2): Ismailia Districts by deviation scores for Independent Dynamic Index (Population characteristics, education resources, Health services resources, NGOs ${ }^{1 *}$ and $\mathbf{C C R}^{2 *}$ ) versus Dependent Dynamic index (neonatal, infant, U5 mortality, $\mathrm{CBR}^{3 *}, \mathrm{CDR}^{4} *$ and $\left.\mathrm{RNI}^{5 *}\right)$ in 2014 versus 2016 


\begin{tabular}{|c|c|c|c|c|c|c|c|}
\hline Districts & IDI2014 & DDI2014 & Net value & Districts & IDI 2016 & DDI2016 & Net value \\
\hline T.Kaber & $13 \%$ & $15 \%$ & $2 \%$ & T.Kaber & $23 \%$ & $21 \%$ & $-3 \%$ \\
\hline Ismailia & $67 \%$ & $-63 \%$ & $-131 \%$ & E.Qantra & $26 \%$ & $-15 \%$ & $-41 \%$ \\
\hline Faied & $-22 \%$ & $30 \%$ & $52 \%$ & A.Swer & $-25 \%$ & $32 \%$ & $57 \%$ \\
\hline E.Qantra & $18 \%$ & $-22 \%$ & $-41 \%$ & Ismailia & $5 \%$ & $-26 \%$ & $-30 \%$ \\
\hline A.Swer & $-32 \%$ & $25 \%$ & $56 \%$ & W.Qantra & $-10 \%$ & $5 \%$ & $15 \%$ \\
\hline Kasasen & $3 \%$ & $3 \%$ & $0 \%$ & Faied & $-30 \%$ & $30 \%$ & $60 \%$ \\
\hline W.Qantra & $-17 \%$ & $-11 \%$ & $5 \%$ & Kasasen & $-21 \%$ & $-3 \%$ & $18 \%$ \\
\hline Total & $32 \%$ & $-25 \%$ & $-56 \%$ & Total & $-32 \%$ & $44 \%$ & $76 \%$ \\
\hline
\end{tabular}

1 *Non-Governmental Organization

$2 *$ Contraception Coverage Rate

3* Crude Birth Rate

4* Crude Death Rate

$5_{*}$ Rate of Natural Increase 